\title{
Mano de obra. El supermercado por dentro
}

Fecha de recepción: 20 de septiembre de 2014

Fecha de aprobación: 27 de octubre de 2014

\section{Resumen}

En la novela Mano de obra (2002), la elogiada narradora y ensayista chilena Diamela Eltit reflexiona en torno a las formas actuales en las que la ancestral práctica de la represión se ejerce y verifica en nuestros días, en la imposibilidad del obrero contemporáneo de organizarse y resistir la opresión, y finalmente en el vaciamiento de la ideología y la pérdida de la memoria que distingue al capitalismo tardío. Para la consecución de estos objetivos, Diamela Eltit reproduce las prácticas de espacio al interior de un supermercado desde el formato de un realty show permitiendo así una interesante reflexión sobre los dispositivos y los instrumentos desde los cuales se manipula y reprime, hoy, al proletario.

Palabras clave: Diamela Eltit; Reality show; Capitalismo tardío; Proletario; Mano de obra.

\footnotetext{
"Artículo de reflexión.
}

Citar: Oliver, F. (enero-junio de 2015). Mano de obra. El supermercado por dentro. La Palabra (26). Páginas 75-84

\section{Felipe Oliver}

Universidad de Guanajuato, México

zamboliver@hotmail.com

"*elipe Oliver es doctor en literatura de la Pontificia Universidad Católica de Chile. Actualmente trabaja como profesor e investigador en el Departamento de Letras Hispánicas de la Universidad de Guanajuato. Es vocero del Cuerpo Académico "Estudios de poética y crítica literaria hispanoamericana", y Coordinador Académico de la Maestría en Literatura Hispanoamericana. 


\title{
la palabra
}

\section{Mano de obra [Labor Force]. The inside of a supermarket}

\begin{abstract}
In the novel Mano de obra [Labor Force] (2002), the acclaimed Chilean novelist Diamela Eltit extends a reflection about the current forms in which the ancient practice of labor exploitation occurs today, taking into account the impossibility of contemporary workers to organize themselves among equals to resist oppression, and finally the lack of ideology and memory that distinguishes late capitalism. To achieve these purposes, Eltit analyzes the daily life of supermarket employees proposing a parallel between the supermarket and a reality show, which allows an interesting reflection on the devices and instruments from which the contemporary proletariat is manipulated and repressed.
\end{abstract}

Key words: Diamela Eltit; Reality show; Late capitalism; Proletariat; Mano de obra [Labor force].

\section{Mano de obra [Main d'ouvre]. Le supermarché à l'intérieur}

\section{Résumé}

Dans le roman Main d'ouvre (2002), la louée narratrice et auteur d'essais chilienne Diamela Eltit réfléchit autour des formes actuelles dans lesquelles l'ancestrale pratique de la répression est exercée et vérifiée de nos jours, dans l'impossibilité de l'ouvrier contemporain, de s'organiser et de résister à l'oppression. Et finalement dans le fait de vider l'idéologie et la perte de la mémoire qui distingue le capitalisme tardif. Pour atteindre ces objectifs, Diamela Eltit reproduit les pratiques de l'espace à l'intérieur d'un supermarché à partir du format d'une émission de télé réalité, permettant ainsi une réflexion intéressante sur les dispositifs et les instruments à partir desquels, le prolétariat est manipulé et réprimé aujourd'hui.

Mots clés: Diamela Eltit ; Télé réalité ; Capitalisme tardif, Prolétariat, Main d’œuvre. 
Para acercarse al universo narrativo de la escritora chilena Diamela Eltit, preguntarse por el espacio es un ejercicio útil. En efecto, sus novelas se despliegan en espacios cerrados y claustrofóbicos en donde los personajes mal intentan sobrevivir. Por ejemplo, en su obra de 1994 Los vigilantes, madre e hijo sufren un encierro autoimpuesto en una precaria residencia en una colonia marginal de Santiago de Chile, mientras que en Jamás el fuego nunca (2007) los personajes no sólo se recluyen en un departamentito sino que además se rehúsan a abandonar la habitación, incluso la cama. Sobre esta obsesión o simple preferencia de Diamela Eltit por los ambientes cerrados y asfixiantes, quisieramos profundizar en las siguientes líneas a través de su novela del 2002 Mano de obra.

La obsesión particular de Diamela Eltit que ciertamente permite agrupar todas sus obras es el ejercicio del poder. Un poder que la autora reconoce entender desde los postulados teóricos de Michel Foucault. Es decir, como el conjunto de prácticas propias de los estados modernos que tienen por objeto subyugar los cuerpos y controlar a la población. Sea por su condición económica, étnica o sexual, los personajes de la autora habitan siempre espacios marginales. En ese sentido, Mano de obra pareciera romper su programa escritural al proponer como espacio central un supermercado prototípico. Después de todo, durante décadas el supermercado se erigió como el símbolo por excelencia de la abundancia y la inagotable oferta material de la así llamada sociedad libre. ¿Quién no recuerda las imágenes de los anaqueles vacíos de los paupérrimos establecimientos comerciales de los países socialistas? ¿Cómo olvidar el incesante tráfico de productos de la canasta básica vendidos a precios exorbitantes en el mercado negro de los países situados del otro lado del muro de Berlín? Sin embargo, Mano de obra apenas si toca la figura del consumidor. Como el título mismo lo sugiere, el énfasis recae en la otra cara de la moneda: el empleado del supermercado, obligado a cumplir turnos de veinticuatro horas, a humillarse frente a los clientes, a permanecer inmóvil durante toda la mañana para escenificar un nacimiento vivo en las fiestas decembrinas. La novela reproduce las formas actuales en las que la ancestral práctica de la opresión se ejerce y verifica en nuestros días, en la imposibilidad del obrero contemporáneo de articular un frente de resistencia y, finalmente, en el vaciamiento de la ideología y la pérdida de la memoria que distingue al sujeto posmoderno atrapado en el modelo económico neoliberal.
La novela se articula en dos partes. La primera de ellas, titulada "El despertar de los trabajadores", reúne ocho monólogos internos de un empleado anónimo del supermercado. Cada monólogo a su vez es precedido por un subtítulo y una referencia espacio-temporal concreta: Verba Roja (Santiago 1918), Luz y Vida (Antofagasta 1909), Autonomía y Solidaridad (Santiago 1924), El proletario (Tocopilla 1904), Nueva Era (Valparaíso 1925), Acción Directa (Santiago 1920), El Obrero Gráfico (Valparaíso 1926), y La Voz del Mar (Valparaíso 1920). Estos subtítulos no han sido tomados al azar: por el contrario, se trata de los distintos diarios obreros que en las primeras décadas del pasado siglo el proletario utilizó para organizarse como cuerpo social y combatir la explotación laboral. Sin embargo, y a diferencia de lo que en primera instancia pudiese sospechar el lector, la novela está lejos de representar una utopía obrera. Al contrario, a lo largo de los monólogos el narrador acepta pasivamente la explotación e incluso llega a (re) configurarse a sí mismo como "una correcta pieza de servicio. ¿Quién soy?, me pregunto de manera necia. Y me respondo: "una correcta y necesaria pieza de servicio" "(p.73). El anonimato y el automatismo del empleado del supermercado, su cosificación como simple pieza de servicio, sugiere entonces que 
no estamos frente a un "yo" sino ante un "nosotros" subalterno, anónimo y atemporal. Dicho con otras palabras, la identidad individual de la voz rápidamente deviene en un colectivo anónimo y fantasmal Así, aunque las referencias espacio-temporales que anteceden cada monólogo varían, la explotación se impone como una práctica omnipresente y hasta inmanente. En palabras de Michael Lazzara,

Está claro que la voz que nos habla ha quedado totalmente desvinculada y desprovista de cualquier red social solidaria. De hecho, a éste trabajador el mismo sistema y los que lo implementan le han negado una identidad propia; lo han reducido al estatus de un mero diente de la rueda capitalista (p.159).

Ya sea en Santiago o en Tocopilla, la explotación está siempre ocurriendo. De hecho, durante esta primera parte todos los verbos aparecen conjugados en tiempo presente. Los diarios obreros y las marcas temporales se convierten entonces en una especie de viñeta que aprehende un momento de la historia del proletariado pero desconectado y descontextualizado del presente. Los diarios funcionan como un recuerdo nostálgico de lo que no fue, del despertar que no se produjo, del sistema que finalmente hundió en un sueño eterno a un colectivo social que en algún momento intentó combatir la explotación.
Mano de obra (de)construye las prácticas de espacio al interior del supermercado; las inverosímiles jornadas de trabajo de los empleados, las prácticas fraudulentas mediante las cuales la empresa pone a disposición del cliente productos en descomposición. Pues más allá del aparato publicitario empeñado en mostrar al supermercado como un espacio amable y dadivoso, en donde la familia transita por entre los anaqueles, con todas las delicias al alcance de la mano, nueva versión del jardín del Edén, el almacén no deja de ser un panóptico. Su arquitectura cerrada, la amplitud de los pasillos, la claridad de los colores, la distribución estratégica de los empleados y las múltiples cámaras de seguridad así lo atestiguan. Si el control consiste en repartir cuerpos en el espacio como afirma Foucault, el supermercado es una de las figuras mejor logradas de rigidez. Un guardia en la puerta para registrar las entradas y salidas; responsables en cada departamento para "atender" (vigilar) a los clientes; cajeros y empacadores vigilándose mutuamente; supervisores patrullando a empleados y clientes; y arriba el lente de la cámara observándonos a todos.

Fiel a su estilo narrativo, en esta primera parte Diamela Eltit pone en funcionamiento una serie de recursos lingüísticos que obstaculizan la fluidez del lenguaje:
Ordeno una a una las manzanas. Ordeno una a una las manzanas, ordeno una a una (las manzanas).

Mientras ordeno (una a una) las manzanas, que ya han entrado en su última fase cosmeticable, logro entender que no dispongo sino de mi apariencia laboriosa desplegada ante el mesón agudamente industrial del súper. Mis días podrían entrar en una considerable cuenta regresiva. (Mi delantal, mi rostro serial y opaco en el espejo). Voy acomodando una a una las manzanas, una y una encima de la otra (p. 55).

El uso exacerbado del paréntesis para decir lo que ya se dijo y repitió hasta el cansancio, la conjunción de "comestible" y "cosmético" en un tercer vocablo, cosmeticable, y el punto y aparte que no muestra una transición de la idea sino su monótona continuidad, desautomatizan la percepción del lector. Tanto la palabra como la sintaxis transgreden las convenciones del lenguaje, construyendo un cuerpo textual otro. Un cuerpo fragmentario, herido, en correspondencia con la percepción esquizoide del narrador, obligado a cumplir con jornadas laborales de hasta veinticuatro horas, con los malestares físicos que eso supone. Como dato adicional, la angustia paranoide ante la mirada omnisciente de los clientes, el supervisor y las cámaras de seguridad. La aplicación conjunta de estas estrategias, el 
monólogo interior de carácter alucinatorio, el lenguaje transgresor, las referencias espacio temporales desvinculadas de la experiencia del narrador, y la presencia del supermercado como el único punto sólido de referencia, inducen al lector a (re)conocer en un espacio de uso cotidiano, y como tal normalizado por la experiencia, una serie de dinámicas perversas.

En la segunda parte de la novela, titulada "Puro Chile", irrumpe en cambio un conjunto de personajes claramente diferenciados entre sí lo mismo por el nombre propio que por sus bien definidos temperamentos: Enrique, Sonia, Isabel, Gloria, Gabriel, Andrés y Pedro. Además de la común vinculación al supermercado, los personajes comparten la residencia. En efecto, y puesto que laboran en el mismo lugar, decidieron rentar una casa y compartir los gastos. Para efectos prácticos constituyen una gran familia. Sin embargo, y he aquí uno de los rasgos esenciales de la novela, lejos de diferenciarse ambos espacios, el supermercado y la casa con todo lo que ello implica - lo público y lo privado, la amenaza exterior frente a la estabilidad interior-, se interfieren hasta confundirse. Partiendo por lo más simple, la casa físicamente luce como el súper:

Andrés tenía la manía de conservar envases, cajas, papeles, productos fallados que se traía del súper. Y después, en las noches, los amontonaba en los pasillos o los apoyaba en las ventanas o los extendía en el suelo como si buscara que la casa misma se convirtiera en un súper de mala muerte (p.115).

Inversión radical, pues de acuerdo con el brillante ensayo de Walter Benjamin "El país del segundo Imperio en Baudelaire”, en sus orígenes la galería, el almacén y el supermercado, al margen de las peculiaridades distintivas de uno y otro, debían remedar al hogar. Al sacar el comercio de la acera para interiorizarlo en un recinto cerrado y controlado, el flâneur encontraba en el almacén un resguardo contra la obscuridad de la calle y la amenaza siempre latente que representa la multitud, la maza obrera e inmigrante que se apoderó de la ciudad. Los pisos de mármol, las estanterías de madera, y el papel tapiz que decoraban las paredes del nuevo recinto comercial pretendían emular a la casa burguesa. El supermercado debía convertirse en una extensión del hogar, a diferencia de lo que ocurre en la novela de Diamela Eltit en donde el segundo imita de mala manera al primero. El orden de los factores sí altera el producto. Pero antes de profundizar en esta dirección, digamos algo sobre los valores simbólicos y afectivos asociados al hogar.

Recordando el famoso libro La poética del espacio (1957) del fenomenólogo francés Gaston Bachelard, la casa es un cuerpo de imágenes que dota al hombre de una ilusión de estabilidad. Esto responde a razones más o menos obvias: en la casa convive la familia y es por lo tanto el único lugar en donde el individuo goza o debiera gozar de un cariño desinteresado. Y más allá de la dimensión social, la morada está íntimamente ligada a la memoria. De acuerdo con Bachelard, los primeros recuerdos de una persona se adhieren por fuerza a las paredes de una residencia, la primera, la así llamada casa familiar. Sin embargo, la dualidad casa/ recuerdo sobrevive ya que el individuo tiende a organizar su biografía y memoria apoyándose en las diferentes residencias que de manera sucesiva ocupó en el devenir del tiempo. Recuperando la terminología lukácsiana, tanto en la dimensión social como en la abstracta, Bachelard configura al individuo a partir del cuerpo de imágenes contenidas y concentradas en el espacio del hogar que posibilitan la ilusión de estabilidad tanto como la reconstrucción de una memoria que legitima la pertenencia en el tiempo y el espacio. El resultado final es esperanzador; si para los existencialistas más pesimistas el hombre no es más que un ser abruptamente arrojado a la nada, el fenomenólogo interpone la morada como una especie de red que amortigua la caída. 
Ahora, aunque Bachelard no llega a mencionar el término "casa burguesa", todo sugiere que su evocación feliz apunta en dicha dirección. El lector modelo del francés, aquel que en el espacio poético descubre imágenes fragmentadas que completa desde el paraíso de la infancia, nada tiene que ver con el sujeto proletario. Por consiguiente, dediquemos también unas líneas a la casa obrera. En un texto titulado Radical Space: Building the House of the People. Margaret Kohn reconstruye la casa de los obreros socialistas europeos de finales de siglo XIX y principios del XX. De acuerdo con Kohn, mucho más que simples unidades habitacionales, el barrio obrero puede y debe ser entendido como un espacio de poder en dos direcciones. Primero, por la obvia exclusión y segregación que se ejerció contra el proletario través de su confinamiento en residencias mono formes y despersonalizadas enclavadas en los márgenes de la ciudad. Medidas destinadas, obviamente, a legitimar y sobre todo perpetuar un tipo específico de organización social y de distribución de la autoridad al catalogar a la clase trabajadora como sujetos antes que individuos, maza antes que colectivo o cuerpo social. Sin embargo, la casa obrera no tardó en convertirse en instituto de enseñanza, centro de debate, teatro, entre otras actividades culturales a fin de generar una conciencia política entre el proletariado. No hay que olvidar que durante décadas, lo mismo en Europa que en Hispanoamérica, asambleas universitarias y gremios obreros estrecharon lazos para crear frentes de oposición contra la explotación. La casa obrera de finales de siglo se convirtió entonces en una heterotopía de resistencia, un espejo en el que el obrero puedo ver reflejada la posición que ocupaba en el espacio social para articular después un frente de oposición.

En Mano de obra, Diamela Eltit despoja a la casa de los atributos que Bachelard y Kohn describen como propios e inherentes al espacio doméstico: estabilidad y memoria para el primero e ideología y discurso para la segunda. Pues más allá de la cercanía material entre el supermercado y el hogar, resultado de la obsesión de Andrés por almacenar los productos, las prácticas de espacio al interior de la casa reproducen la dinámica del súper. El sistema de jerarquías y abusos, de explotador y explotados que rige y distingue al almacén encuentra un correlato a escala en el interior de la casa. Enrique, por ejemplo, es maltratado por los superiores en el súper pero en la casa dirige con arbitrariedad el destino y las reglas que los demás habrán de respetar: distribuye a los numerosos residentes en los pocos dormitorios, estable- ce un horario para apagar la luz y hasta decide el canal de televisión que todos deben mirar. Por su parte, Isabel presta su cuerpo a la lasciva de los supervisores como si se tratara de una parte más de sus funciones $\mathrm{u}$ obligaciones laborales, y Gloria hace lo propio en la casa. El supermercado y la casa simbólicamente se convierten en un mismo y único espacio ya que los personajes trasladan del uno a la otra las mismas conductas enviciadas creando un ambiente opresivo ahí en donde se supone que debiera imperar el afecto y la paz. De hecho, de acuerdo con las reglas establecidas por los empleados-residentes, la casa no admite cesantes ni enfermos, por lo que la permanencia en el hogar depende de la continuidad laboral.

Otro tanto ocurre con los afectos: en las primeras páginas de la segunda parte de la novela Isabel es descrita con admiración como cariñosa, respetuosa y considerada, y poco más adelante sus compañeros no dudan de adjetivarla de "huevona, maricona, culiada y egoísta” (p. 150). Al igual que la mercancía en el supermercado, los afectos son transferibles, casuísticos y redituables. De hecho, el respeto y el cariño no surgen de manera espontánea ni tampoco se ganan con el tiempo: se imponen, forman parte de un contrato preestablecido y como tal sujeto a evaluación: 
...Sonia se había venido a vivir con nosotros. De malas ganas. Pero, finalmente, se había percatado que estaba obligada a querernos. Nosotros se lo habíamos exigido. Necesitábamos una cantidad considerable de respeto y de cariño. Enrique lo expreso con toda claridad: "o si no a esta mierda la echamos a la calle. En pelotas. A poto pelado. Con una mano por delante y la otra por detrás" lo dijo fríamente. De la misma manera en que ahora empezaba a entregarnos a las nuevas instrucciones. Fríamente. Una tras otra (p.108).

El pasaje es tan elocuente que apenas si requiere un comentario: el respeto y el cariño forman parte de una lista de instrucciones que se enumeran fríamente. Y como toda instrucción, su violación o no cumplimiento acarrea una medida punitiva. En este caso la expulsión del súper-casa, con una mano por delante y otra por detrás. Una vez que los afectos han sido provistos de un valor de cambio, es inevitable entonces que los personajes intenten lucrar con ellos mediante alianzas, chantajes e intrigas. De acuerdo con Zygmunt Bauman,

El blanco principal del ataque de los mercados son los humanos en cuanto productores. Una vez conquistada y colonizada toda la tierra, sólo los consumidores obtendrán su permiso de residencia. El difuso albergue donde se alojaban las condiciones de vida compartida serán clausurado y desman- telado. Los modelos de vida, así como los tipos de vínculos que los sostienen, sólo estarán disponibles bajo la forma de "bienes" (p.102).

Cada personaje utiliza entonces lo poco que tiene no tanto para crecer como para hundir al resto. El caso más patético es sin duda el de Gloria, cuyo único bien consiste en su cuerpo. Lo que no es menor, pues en su momento logra aprovecharse de la "calentura" de Andrés para urdir una conspiración en contra del resto de los convivientes:

Andrés se lo contó a Enrique. En la mañana, temprano. Se lo confió bajo estricto secreto. Le dijo que Gloria le había propuesto cagarnos para que nos echaran de una vez por todas del súper. Le confesó que Gloria le había pedido que él hiciera lo que fuera necesario para que entráramos a las listas. Que no nos advirtiera ni una palabra. Que se quedara callado. Y le dijo, también, que después ellos iban a seleccionar a los nuevos trabajadores que iban a ocupar la casa (p.116).

No ha sido mencionado todavía que de entre los personajes de la novela Gloria es la única que no labora en el supermercado. Habita en la casa sólo porque en su momento se ofreció a encargase de la comida y el aseso. No recibe un salario, duerme en un cuartito al fondo de la casa, y acepta que los varones la monten como una más de sus funciones. Las prácticas de espacio al interior del hogar guardan muy poca relación con el ideal de la gran familia unida y feliz que sustenta la ficción nacional. Para nadie es un secreto que la familia como institución ha sido objeto de una compleja construcción simbólica como el pilar y garante moral que sostiene a la sociedad. Sin embargo, "en estas agrupaciones transitorias el espacio privado y las relaciones afectivas toman el lugar de las relaciones laborales, produciendo la vinculación en términos de metas y logros" (Blanco, 2006, p.179). Bajo esta óptica, no es descabellado comparar la convivencia al interior de la residencia con un reality show. En efecto, los convivientes dicen quererse y respetarse al mismo tiempo que conspiran entre sí para eliminarse. Ingresar a la lista de nominados del supervisor, ya lo hemos visto, constituye la mayor amenaza. Asimismo, la novela termina con el ascenso laboral de Enrique y la subsecuente expulsión del súper-casa del resto de los personajes. Imagen tomada del Gran Hermano: mientras los perdedores abandonan desolados la residencia, marchando hacia un destino anónimo y gris, el ganador toma posesión en solitario de la totalidad del espacio. No es casual que el premio recaiga en el más cínico y cruel de todos, aquel que lejos de construir lazos sinceros que ayudaran a mantener 
la cohesión del grupo esperó en la sombra el momento idóneo para eliminar de golpe a sus semejantes.

Por su parte, Rubí Carreño en Memorias del nuevo siglo: jóvenes, trabajadores y artistas en la novela chilena reciente compara la lista de los supervisores del supermercado con la lista del supervisor de los campos de concentración. Lo anterior a partir de la obligación por parte de los empleados del súper de lucir sanos y deseables, y de la obsesión de la empresa por mantener la productividad a costa de la vida humana. Trátese de un campo de concentración o de un show de televisión, en cualquier caso la alienación, el individualismo y la desechabilidad no son los peros negativos del modelo económico sino las virtudes que reciben recompensa. Las relaciones afectivas o la ideología lejos de proteger al sujeto obstaculizan su crecimiento profesional. Por consiguiente, los valores que Bachelard y Kohn su momento encontraron concentrados en el hogar, cada uno enfocándose en un sustrato social diferente, ceden terreno a la relaciones contractuales que definen al no-lugar, recuperando el concepto de Marc Augé. En el actual modelo económico neoliberal, los antes bien diferenciados espacios burgueses y proletarios lentamente se ven sustituidos por lugares que el sujeto usa más no habita, por los que transita sin arraigar y en donde los derechos, mínimos por cierto, dependen de circunstancias temporales y etéreas (poseer un billete de avión, mostrar una identificación, comprometerse a comprar un producto, abandonar el espacio a determinada hora, etc).

Ahora, el escenario laboral que pone en tensión la novela responde al tránsito del fordismo al posfordismo. Entendiendo por esto el paso de una economía caracterizada por los empleos estables a largo plazo típicos del trabajo fabril por las relaciones laborales flexibles, móviles y precarias: flexibles porque el trabajador debe adaptarse a tareas diferentes; móviles porque salta con frecuencia de unos puestos a otros; precarias porque ya no hay contratos que garanticen un empleo estable a largo plazo (Hardt, 2004, p.141).

Dadas las condiciones de trabajo contemporáneas, el "neobrero" ya no es valorado por su capacidad técnica para ejecutar un trabajo especializado o, en su defecto, por su fuerza bruta (los famosos brazos que transforman al trabajador migrante en bracero), sino por su histrionismo, carisma y apariencia:

Fatigados por el trabajo de mantener intactas nuestras sonrisas en los pasillos[...] Desolados ante la reiteración de preguntas idiotas, acostumbrados penosamente a que nos gritaran, que nos obligaran a disfra- zarnos. Que nos vistieran de viejos pascueros en $\mathrm{Na}$ vidad, de osos, gorilas, de plantas, de loros, de pájaros locos los domingos. Que nos impusieran el deber de bailar cueca el 18, de bailar jota el 12 de Octubre ... (p.111).

Todo es imagen y nada es contenido. Desenvolverse con éxito en el supermercado supone proyectar una imagen que agrade la mirada de los clientes-espectadores y mostrar la disponibilidad necesaria para ejecutar un sketche, caracterizar a un personaje, montar una coreografía y, en síntesis, ejecutar cualquier sandez "entretenida”. El trabajo, contaminado por la universalidad del espectáculo, se convierte en performance y trabajador en animador o botarga. No en vano el "ganador" del reality de la novela, Enrique, destaca por sobre el resto de los empleados-residentes gracias a su habilidad para montar en cualquier instante un número para seducir a los clientes:

... el gentío luchaba por llegar hasta los tarros ubicados en el pasillo 2 donde radicaba la oferta que Enrique dirigía desde la caseta con ganas, con bronca, con un impulso que no nos imaginábamos y que conseguía que los clientes se abalanzaran por el pasillo, gracias a la convicción impostergable que emanaba de la voz de Enrique. Una voz que conseguía darle una categoría nacional a los tarros de papayas y lograba, especialmente, que el 
jefe de los supervisores se sintiera seguro, satisfecho, conmovido por la respuesta de la multitud a la voz terriblemente convincente y exitosa de Enrique (pp. 159-160).

Un dato significativo: al mismo tiempo que Enrique presenta con especial convicción las bondades de los tarros de papaya almibarada, desplegando en la tarea sus cualidades histriónicas, Isabel exhibe un pelador de patatas ante un grupo de clientes. Sin embargo, no logra retener el interés de los espectadores, acaso por carecer de la espectacularidad del altoparlante y la caseta de animación. Páginas después Isabel abandona el súper-casa, y Enrique es ascendido a supervisor. El mundo anglosajón posee un término específico para referirse a la sub-industria del espectáculo construida alrededor de personas de un sólo uso: disposable people (personas de desecho). Término del que nadie está salvo en el modelo económico vigente.

Uno de los rasgos más atractivos de la novela, y que sin duda refleja el dominio narrativo de Eltit, estriba en que el texto jamás precisa el número exacto de residentes. No es posible determinar cuántos ni quiénes habitan en la casa pues conforme se suceden las páginas irrumpen nuevos personajes. O mejor dicho, se hace evidente la presencia de residentes que hasta ese momento no habían sido siquiera mencionados en el texto. Como si un control remoto superior hiciese zapping entre los personajes, Alberto aparece y desparece de la novela en el tercer segmento narrativo, Gabriel irrumpe a partir del cuarto, Sonia hace lo propio a partir del séptimo, Andrés en el noveno y Pedro en el decimotercero. Al final, el lector sabe a ciencia cierta que en la casa cohabitan Enrique, Sonia, Isabel, Gloria, Gabriel, Andrés y Pedro, y que Alberto alguna vez vivió en ella pero fue expulsado al haber puesto en peligro los puestos de trabajo de los demás al intentar sindicalizarse. Sin embargo, es inevitable preguntarse si hay alguien más en la casa pero "se acabaron las páginas" antes de que su presencia nos fuera revelada. Esto genera en lector una atmosfera de incertidumbre y volatilidad que nada tiene que ver con las imágenes de estabilidad y arraigo que el sujeto debiera encontrar en su morada; al contrario, como los objetos de un sólo uso que pueblan los anaqueles del almacén, idénticos entre sí, fabricados en serie, sin memoria ni discurso, los residentes entran y salen de la casa tal como los personajes entran y salen de la novela o como los clientes entran y salen del súper.

Para finalizar, quisiéramos volver a los diarios obreros con los que abren los segmentos narrativos que componen la primera parte de la novela. Ya ha sido mencionado que se trata de publicaciones de carácter socialista y anarquista que circularon muchas veces de manera clandestina durante las primeras décadas del pasado siglo, y que pretendían concientizar al proletariado en la lucha de clases. La utilización de estos títulos como encabezado pretende evocar un pasado en el que la utopía obrera era todavía creíble. En consonancia con este propósito, la segunda parte de la novela se subtitula "Puro Chile", nombre del último diario obrero que circuló en el país sudamericano, y lleva como marca temporal el año de 1970. Fecha axial en la historia reciente de Chile pues remite a la victoria electoral de Salvador Allende. Sin embargo, bien lo sabemos, el que prometía ser el triunfo definitivo del proletario chileno pronto devino en la violenta y definitiva derrota no sólo de la clase obrera, sino de toda una generación unida por la común ideología. De ahí que al girar la página y sumergirse en la segunda parte de la novela, el lector se enfrente a un grupo obrero sin contratos fijos de trabajo, con salarios y horarios variables y sin iniciativa, memoria ni discurso. De ahí que al girar la página los diarios obreros utilizados como subtítulos desaparecen y los segmentos narrativos poseen encabezados como "Enrique le gritó a Pedro" y "Sonia lloró en el baño" que parodian el lenguaje banal y sensaciona- 
lista de periódicos contemporáneos chilenos como Las últimas noticias y La cuarta que han encontrado en la farándula el medio idóneo para seducir a los lectores y acaparar el mercado. Ya no hay debate, crítica y reflexión, ni siquiera información. Pero que no cunda el pánico; mediante el espectáculo lo cotidiano deja de ser trivial para convertirse en entretenimiento, en "cultura".

Recapitulando, en Mano de obra Diamela Eltit vuelve sobre temas siempre vigentes como el trabajo, la familia, el espacio público y el espacio privado para reflexionar sobre el lugar que ocupan en el siglo XXI. Si en el pasado la autora se centró en la dictadura militar encabezada por Pinochet para reflexionar en torno el autoritarismo, la represión y el extermino de los grupos sociales menos favorecidos, al ingresar al presente siglo su mirada se avoca a describir las prácticas de espacio al interior del supermercado y su infiltra- ción en las estructuras sociales más elementales como la familia. El modelo económico neoliberal es representado entonces como un poder omnipresente que excluye y oprime al individuo con una eficiencia tal que vacía de contenido o validez las preguntas por el género, la raza o la nacionalidad. Hasta hace unas décadas, el obrero podía todavía apelar a su especialización para exigir un mínimo de concesiones. Hoy no puede negar su naturaleza desechable.

\section{Referencias}

Bachelard, G. (1965). Poética del espacio. (T. Champourcín). México: Fondo de Cultura Económica.

Bauman, Z. (2006). Amor Líquido, acerca de la fragilidad de los vínculos humanos. (Mirta Rosenberg y Jaime Arrambide). Buenos Aires: Fondo de Cultura Económica.

Benjamin, W. (1972). El país del segundo Imperio en Baudelaire. (J. Aguirre). Poesía y capitalismo. Iluminaciones II. Madrid: Taurus.

Blanco, F. (2006). Poéticas de alienación y muerte en Mano de obra. En: B. Llano. Letras y proclamas. La estética literaria de Diamela Eltit. Santiago de Chile: Cuarto propio. 177-199.

Carreño, R. (2009). Memorias del nuevo siglo: jóvenes, trabajadores y artistas en la novela chilena reciente. Santiago: Cuarto propio.

Eltit, D. (2002). Mano de obra. Santiago de Chile: Planeta.

Hardt, M. y A. N. Hardt (2004). Multitud. Guerra y democracia en la era del Imperio. (J. A. Bravo). Buenos Aires: Debate.

Kohn, M. (2003). Radical Space: Building the House of the People. Ithaca: Cornell University Press.

Lazzara, M. J. (2009) Estrategias de dominación y resistencia corporales. Las biopolíticas del mercado en mano de obra de Diamela Eltit. En: Diamela Eltit: Redes Locales, Redes Globales. En: R. Bolívar. Madrid: Iberoamericana. 144-165. 